\title{
ANTIOXIDANT CAPACITY OF THE KIDNEY TISSUE IN PATIENTS WITH RENAL CELL CARCINOMA
}

\section{Ivan Pavlovićc ${ }^{*}$ Ana Todorović, Vesna Stojiljković, Ljubica Gavrilović, Nataša Popović, Snežana B. Pajović, Snežana Pejić}

Laboratory of Molecular Biology and Endocrinology, "Vinča” Institute of Nuclear Sciences, University of Belgrade, Belgrade, Serbia

\begin{abstract}
Renal cell carcinoma is the most common and the most lethal type of kidney cancer with the highest incidence in developed countries. At the moment of diagnosis, many patients already have developed metastases. Tobacco smoking, obesity, hypertension and occupational exposure are established risk factors. Superoxide dismutase (SOD), catalase (CAT) and glutathione peroxidase (GPX) are antioxidant enzymes (AOE) that have a key role in protecting from reactive oxygen species (ROS) produced in pathological processes. We examined the antioxidant capacity of tumour tissue in patients with clear cell type of renal cell carcinoma. The results showed a significant decrease of $A O E$ activities in the tumour tissue compared to the normal kidney tissue, indicating that the tumour tissue is under permanent oxidative stress. Renal cell carcinoma is highly resistant to radiation therapy, which is also associated with free radical production. Since the tumour tissue has impaired AO capacity, the findings of this study may contribute to the improvement of the potential therapeutic treatments.
\end{abstract}

Key words: Oxidative stress, antioxidant enzymes, kidney cancer

DOI: $10.21175 /$ RadProc.2016.36

\section{INTRODUCTION}

The majority of neoplastic changes in kidneys belong to renal cell carcinoma (RCC) (almost 90\%). Predominant histological form of this cancer is clear cell or conventional type which accounts for $75 \%$ of all cases. Clear cell RCC arises from epithelial cells of the proximal tubules. Their active role in reabsorption and secretion makes them vulnerable to the effects of potential carcinogens. This is in accordance with data that only $2 \%$ of all cases have hereditary basis [1].

Renal cell carcinoma is an asimptomatic disease with frequent metastases, highly resistant to radiation therapy and standard chemotherapy [2]. Established risk groups are active or passive smokers, obese people, people with hypertension and those who are exposed to carcinogenic compounds such as arsenic or cadmium. Patients with end stage of renal disease (ESRD) or acquired cystic kidney disease (ACKD) are also under the risk [3]. Incidence rates are higher in Europe, North America, and Australia, compared to Asia, while are the lowest in Africa [4,5].

Reactive oxygen species (ROS) have a role as signalling molecules in process of redox regulation. Physiological level of ROS, which is essential to accomplish this role, is maintained by antioxidant enzymes (AOE). Superoxide dismutases (SODs) catalyze reduction of superoxide anion $\left(\mathrm{O}_{2}{ }^{-}\right)$to hydrogen peroxide $\left(\mathrm{H}_{2} \mathrm{O}_{2}\right)$. Hydrogen peroxide is a substrate for catalase (CAT) and glutathione peroxidase family (GPx) that reduce $\mathrm{H}_{2} \mathrm{O}_{2}$ into water thus preventing Fenton's reaction [6]. Impaired activity of $\mathrm{AO}$ enzymes may lead to excessive production of ROS and consequently to different disorders.

The relationship between cancer and antioxidants is in the scientific focus for many years. The main reason is a dual role of antioxidants in neoplastic disorders. Antioxidants can suppress carcinogenesis by ROS elimination, but also to promote it by allowing the survival of metabolically changed cells [7]. In this study, we examined the antioxidant status of tumour tissue in patients with clear cell type of renal cell carcinoma.

\section{Methods}

Subjects. The study was conducted on 16 patients with clear cell type of RCC who underwent radical nephrectomy. Tumour tissue specimens were obtained after the surgery. Normal tissue samples were taken from distant part of the same kidney. All tumour tissue samples were examined by a clinical pathologist at the Medical Faculty, University of Belgrade and classified as grade II by Fuhrman grading system. The study was approved by the Ethics Committee of Medical Faculty, University of Belgrade and Ethics Committee of Clinical Center "Dr Dragiša Mišović-Dedinje“. Informed consent was obtained from every patient. Tissue samples were washed in saline solution, then homogenized in phosphate buffer $\left(0.05 \mathrm{mM} \mathrm{KH}_{2} \mathrm{PO}_{4}\right.$ and $0.1 \mathrm{mM}$ EDTA, $\mathrm{pH} 7.4$ ) and frozen at $-70^{\circ} \mathrm{C}$ for $20 \mathrm{~h}$ to disrupt cell membranes. Thawed homogenates are vortexed for $1 \mathrm{~min}$ and centrifuged at $10000 \times \mathrm{g}$, for 15

\footnotetext{
*pavlovic@vinca.rs
} 
minutes at $4^{\circ} \mathrm{C}$. The upper aqueous layer was collected and used for enzyme activity assays. Enzyme activities were expressed as units per milligram of protein (U/mg). For the protein concentration measurement, we used Pierce ${ }^{\mathrm{TM}}$ BCA Protein Assay Kit (Thermo Fisher Scientific, Inc., Waltham, MA, USA).

Enzyme assays. Measurement of SOD and GPx activity is performed by using commercial kits, Superoxide Dismutase Assay Kit (Cayman Chemical, Ann Arbor, MI, USA) and Oxis Bioxytech $\AA$ GPx-340 (Oxis International, Inc., Portland, OR, USA). Catalase activity is measured by the method of Beutler [8].

Statistics. GraphPad Prism (San Diego, CA, USA) software was used for statistical analysis. The significance in enzyme activities between normal and tumour tissue was determined using a paired t-test.

\section{RESULTS}

Total SOD activity in normal and tumour kidney tissue is presented in Figure 1 . We found a significantly decreased SOD activity in tumour tissue compared with the normal kidney tissue $(\mathrm{p}<0.001)$. The catalase activity is shown in Figure 2. Unlike the normal kidney tissue, tumour tissue had dramatically impaired CAT activity $(\mathrm{p}<0.001)$. A similar pattern was observed for glutathione peroxidase activity (Figure 3). Tumour tissue showed a significantly decreased GPx activity in comparison to normal renal tissue $(\mathrm{p}<0.001)$.

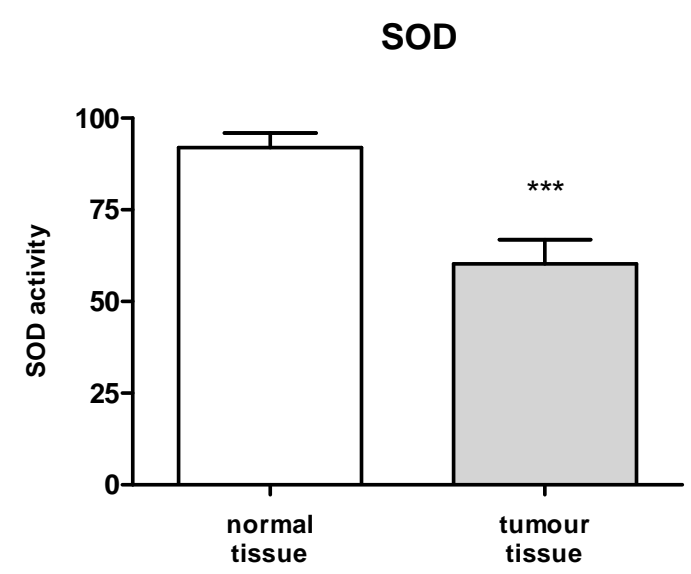

Figure 1. Total SOD activity in normal and tumour kidney tissue of patients with clear cell RCC. Activity is expressed as Units per milligram protein $(\mathrm{U} / \mathrm{mg})$. Significance: $* * *$ $\mathrm{p}<0.001$ (paired t-test)

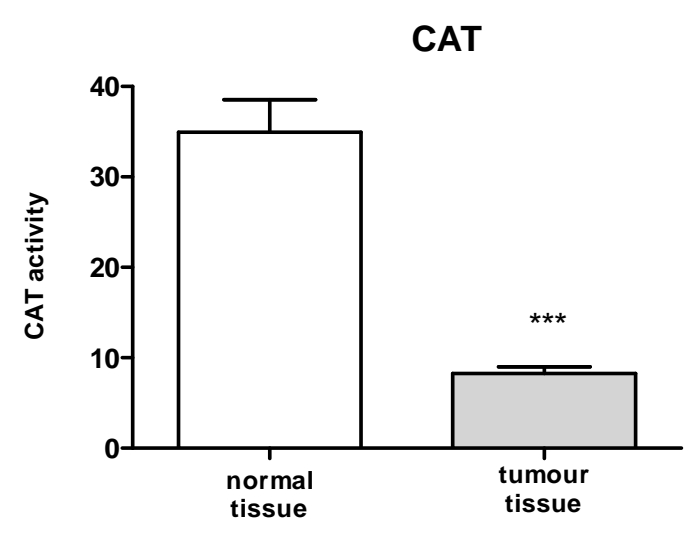

Figure 2. CAT activity in normal and tumour kidney tissue of patients with clear cell RCC. Activity is expressed as Units per milligram protein (U/mg). Significance: ${ }^{* * *}$ p $<0.001$ (paired t-test)

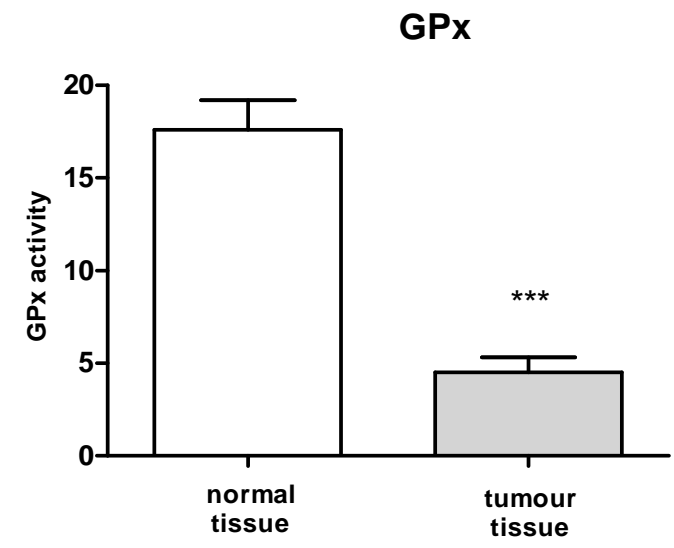

Figure 3. GPx activity in normal and tumour kidney tissue of patients with clear cell RCC. Activity is expressed as Units per milligram protein $(\mathrm{U} / \mathrm{mg})$. Significance: ${ }^{* * *} \mathrm{p}<0.001$ (paired t-test)

\section{DISCUSSION}

Oxidative stress may contribute to malignant transformation of normal cells as well as to proliferation of malignant cells. In this study, we examined the activities of SOD, CAT and GPx as the first defence line against oxidative stress.

We observed a significant fall of SOD activity in tumour tissue of the kidney in patients with clear cell type of RCC which implies that malignant tissue has a lower ability to eliminate superoxide anion radical $\left(\mathrm{O}_{2}{ }^{-}\right)$. In previous study, a decreased activity of total SOD was also observed [9]. Opposite to these results, Ganesamoni et al. [10] found the increased activity of SOD in tumour tissue compared to normal kidney tissue.

Decreased activity of CAT in tumour tissue, in our study, correlates with the lower expression of this enzyme in the clear cell type of RCC found by Soini et al. [11]. Same authors also observed a positive expression of AO enzymes in normal kidney tissue which corresponds to higher activity of these enzymes recorded in our study. We observed significantly lower 
activity of GPx in tumour tissue and this finding is in accordance with previous reports [9,12]. The impaired activity of CAT and GPx, the enzymes that have a role to eliminate $\mathrm{H}_{2} \mathrm{O}_{2}$ and organic peroxides, may increase lipid peroxidation caused by oxidative stress. Excessive production of superoxide anion radical as a result of lower SOD activity could be an additional factor that contributes to lipid peroxidation. Increased lipid peroxidation is proposed as a potential molecular pathway for the increased risk of renal cell carcinoma [13]. Gago-Dominguez and Castealao [14] hypothesized that apoptosis induced by lipid peroxidation could be responsible for the loss of function of VHL gene. The VHL gene is a tumour suppressor gene and the majority of patients with sporadic (non-inherited) clear cell RCC have acquired dysfunction of VHL protein [15].

In conclusion, our results show a low antioxidant capacity of the tumour tissue in clear cell RCC. Decreased enzyme activity suggests that tumour tissue is under permanent oxidative stress which may be a contributing factor in RCC initiation and development.

Acknowledgement. This study was financially supported by the Ministry of Education, Science and Technological Development (Grant III 41027).

\section{REFERENCES}

1. G. Martignoni, R.Tardanico, M. Pea, M. Brunelli, S. Gobbo and V. Ficarra, "Renal tumors", in Clinical Pathology of Urologic Tumors, G. Mikuz, Ed. London: Informa Healthcare, 2007, pp. 1-41

2. E. Jonasch, A. Futreal, I. Davis, S. Bailey, W. Y Kim, J. Brugarolas et al, "State of the science: An update on renal cell carcinoma”, Mol. Cancer Res. vol. 10, pp. 859-880, 2013

3. P. Cairins, "Renal cell carcinoma", Cancer Biomark., vol. 9, pp. 461-473, 2011.

4. B. Ljungberg, S.C. Campbell, H.Y. Choi, D. Jacqmin, J.E. Lee, S. Weikert and L.A. Kiemeney, "The epidemiology of renal cell carcinoma", Eur. Urol., vol. 6o, pp. 615-621, 2011
5. A. Znaor, J. Lortet-Tieulent, M. Laversanne, A. Jemal and F. Bray, "International Variations and Trends in Renal Cell Carcinoma Incidence and Mortality", Eur. Urol., vol. 67, pp. 519-530, 2015

6. B. Halliwell and J.M.C. Gutteridge, Free Radicals in Biology and Medicine, $4^{\text {th }}$ ed., Oxford: Oxford University Press, 2007

7. B. Poljšak and I. Milisav, "The Neglected Significance of Antioxidative Stress", Oxid. Med. Cell. Longev., vol. 2012, pp. 12 pages, 2012

8. E. Beutler, "Catalase," in Red cell metabolism: a manual of biochemical methods, E. Beutler, Ed., Orlando: Grune and Stratton, Inc., 1984, pp.105106

9. I. Durak, Y. Bedük, M. Kavutcu, S. Oztürk, O. Canbolat and S. Ulutepe, "Activities of superoxide dismutase and glutathione peroxidase enzymes in cancerous and non-cancerous human kidney tissues“, Int. Urol. Nephrol., vol. 29, pp. 5-11, 1997

10. R. Ganesamoni, S. Bhattacharyya, S. Kumar, A. Chauhan, U.K. Mete, M.M. Agarwal, R. Mavuduru et al, "Status of Oxidative Stress in Patients With Renal Cell Carcinoma”, J. Urol., vol. 187, pp. 11721176, 2012

11. Y. Soini, J.P. Kallio, P. Hirvikoski, H. Helin, P. Kellokumpu-Lehtinen, T.L. Tammela, M. Peltoniemi, P.M. Martikainen and L.V. Kinnula, "Antioxidant enzymes in renal cell carcinoma", Histol. Histopathol., vol.21, pp. 157-165, 2006

12. M. Pljesa-Ercegovac, J. Mimic-Oka, D. Dragicevic, A. Savic-Radojevic, M. Opacic, S. Pljesa, R. Radosavljevic and T. Simic, "Altered antioxidant capacity in human renal cell carcinoma: Role of glutathione associated enzymes", Urol. Oncol., vol. 26, pp. 175-181, 2008

13. M. Gago-Dominguez, J.E. Castelao, J.M. Yuan, R.K. Ross and M.C. Yu, "Lipid peroxidation: a novel and unifying concept of the etiology of renal cell carcinoma (United States)", Cancer Causes Control, vol. 13, pp. 287-293, 2002.

14. M. Gago-Dominguez and J.E. Castelao, "Lipid peroxidation and renal cell carcinoma: Further supportive evidence and new mechanistic insights", Free Radic. Biol. Med., vol. 40, pp. 721-733, 2006

15. B.I. Rini, S.C. Campbell and B. Escudier, "Renal cell carcinoma“, Lancet, vol. 373, pp. 1119-1132, 2009 